\title{
What are EMEUNET and the Section of Young Rheumatologists of the Polish Society for Rheumatology?
}

One of the objectives of EULAR was and still is to involve in its activities the generation of young rheumatologists. The first initiative was the creation in 2009 and the development of EMEUNET (The Emerging EULAR Network) - a Europe-wide network of young rheumatologists. Its mission is to satisfy the educational needs and promote young researchers. The first members of EMEUNET were Maya Buch (United Kingdom), Laure Gossec (France) and Daniel Aletaha (Austria). EMEUNET also supports integration with EULAR activities through inter-generational cooperation and promoting creative engagement of young people. The role and recognition of EMEUNET is growing - in 2014 EULAR made it mandatory to involve two members of EMEUNET when forming a working group to develop EULAR clinical recommendations. A Working Group of 25 young rheumatologists was also established. Initially the members of the Working Group were recommended by EULAR; however, since 2012 an application process of entry into the Working Group has been set up. The application process is competitive and takes place annually in spring - the EMEUNET members are informed of the process by email. Each member can apply to enter the Working Group, and four Polish members have already been successful.

The main objective of EMEUNET is to enhance the quality of education among young rheumatologists and researchers by: developing and publishing own educational materials, organizing competitions and mentoring, delegating EMEUNET observers on the Standing Committees of EULAR, participating in the development of EULAR recommendations, organizing sessions at the EULAR scientific congress, and carrying out surveys on educational needs of young rheumatologists. EMEUNET also supports research and collaboration among rheumatologists by establishing a database of young rheumatologists and of researchers working in the field of rheumatology, supporting exchange of technical data and medical knowledge, organizing meetings of young rheumatologists with their mentors, and informing young Europeans on the organization, mission and activities of EULAR. EMEUNET disseminates the information on its website, through newsletters, social media (Facebook, Twitter) as well as the network of EMEUNET Country Liaisons in EULAR member countries. Not only rheumatologists can become members of EMEUNET, but also representatives of related specialties as well as academics.

Poland has also contributed to the activities of the EMEUNET network. Jan Sznajd (Kraków) has become the first member of the Working Group, first Country Liaison for Poland as well as the first chairperson of the Section of Young Rheumatologists of the Polish Society for Rheumatology. At present three members represent Poland in the EMEUNET working group: Marcin Milchert (Szczecin), since 2014 a member of the Education Subgroup and Country Liaison Subgroup as well as Country Liaison for Poland; Anna Olewicz-Gawlik (Poznań), since 2015 a member of the Country Liaison Subgroup; and Joanna Zalewska (Bydgoszcz), since 2015 a member of the Newsletter Subgroup and Peer Mentoring Subgroup. At the moment Poland is represented in EMEUNET by 37 regular members - this number increased by 32 persons within the last two years.

More information on EMEUNET can be found on the website - the members are also kept informed. EMEUNET Member Registration is available at: http://emeunet.eular.org/members_registration.cfm

The objective of the Section of Young Rheumatologists of the Polish Society for Rheumatology, which is active in Poland, is to integrate the community of young rheumatologists as well as education and research. Only those under 45 years old can become members of the Section. The structure of the Polish organization is similar to EMEUNET - the activities are based on the Working Group structure. Unlike EMEUNET, membership in the Section of Young Rheumatologists is limited to rheumatologists or doctors specializing in rheumatology. However, as a Polish organization of young rheumatologists we would like to change this rule in order to allow for the integration of specialists and researchers with whom we cooperate on a daily basis. The Section of Young Rheumatologists of the Polish Society for Rheumatology and EMEUNET have similar objectives. However, our national members have different needs, and we are operating in a different reality. The possibilities offered by EMEUNET are not fully in line with the scope of the Polish organization; therefore we encourage membership in both networks. Thanks to the involve- 
ment of the Section's Working Group, many projects are being carried out, including the sponsorship of educational events abroad for Section members.

In 2015 a project aimed at the participation of young rheumatologists in the EULAR Congress was organized and welcomed with great interest. Thanks to the generosity of the sponsors we have been able to obtain funding in two categories: for young researchers and practicing doctors. The Working Group has developed criteria that allowed for an objective selection of candidates. The project will be continued next year. We have also been carrying out a project called "Pytania do eksperta" ("Questions for the expert"), published in the quarterly Przeglad Reumatologiczny ("Rheumatological Review"), where the experts answer the questions of young rheumatologists and their responses are illustrated by a specific clinical case.

A course on the use of ultrasound examination in the diagnosis of large vessel vasculitis is also carried out. In 2016 a third workshop on ultrasound application in diagnosis of giant cell arteritis is planned to be organized, its objective being to increase the diagnostic awareness of the most common of primary vasculitis and prevent related complications. The course is organized by the Department of Rheumatology and Internal Medicine of the Pomeranian Medical University in Szczecin, where the fast track diagnosis of giant cell arteritis has been introduced. The funding has been ensured by an educational grant from Bilateral Fund (Norway Grants). The course is intended mainly for young rheumatologists as well as rheumatologists performing ultrasound examinations of the musculoskeletal system. The training will be conducted by lecturers and instructors from the Pomeranian Medical University, but also by leading experts in the field: Professor Wolfgang Schmidt from Berlin and Dr Andreas Diamantopoulos from Norway.

A session organized by the Section of Young Rheumatologists will take place at the conference called "Szczecińsko-Poznańskie Spotkania Reumatologiczne" ("Szczecin-Poznan Rheumatology Meetings"), which will be held on 12-14 May 2016 in Kołobrzeg.

An important objective of the Section is to increase the involvement of Poles in EMEUNET and their international activities, as well as active membership in the Polish Society for Rheumatology. The advantages of EMEUNET membership are receiving newsletters and current information on international educational possibilities, scholarships, grants, conferences and employment opportunities. The Polish Section has also been publishing a newsletter, including information on scientific contributions, reports from scholarships as well as practical information on the possibilities of professional and scientific development. Members of the Section have participated in an international study, initiated by EMEUNET, on the diversification of specialised training in rheumatology in different European countries as well as on the need of palliative care in rheumatology in Poland. The Section also participates in the discussion on the programme of specialized training in rheumatology. An open letter has been addressed by the Working Group to the national consultant in the field of rheumatology, the president of the Polish Society for Rheumatology as well as to the chairman of the Commission for Specialized Training and Lifelong Learning of the Polish Society for Rheumatology. The letter presented reservations related to the forms of training, together with proposals for changes. The national consultant has taken these proposals into consideration and some of them have been included in the new specialties programme.

The Section of Young Rheumatologists makes use of social media, such as Facebook and Twitter, and can also be found on the website of Medycyna Praktyczna (Practical Medicine): http://www.mp.pl/reumatologia/. A sub-site of the Polish Society for Rheumatology website has been designed and includes information about the Section as well as the application form. We encourage everyone to use the potential of the Section to organize multicentre research studies and educational initiatives as well as to support common activities aimed at the development of rheumatology in Poland and abroad. You are welcome to register at: http://www.reumatologia.ptr.net.pl/?formularz-zgloszeniowy,57.

Marcin Milchert, MD, PhD Chairman of the Section of Young Rheumatologists of the Polish Society for Rheumatology Department of Rheumatology and Internal Medicine of the Pomeranian Medical University in Szczecin 